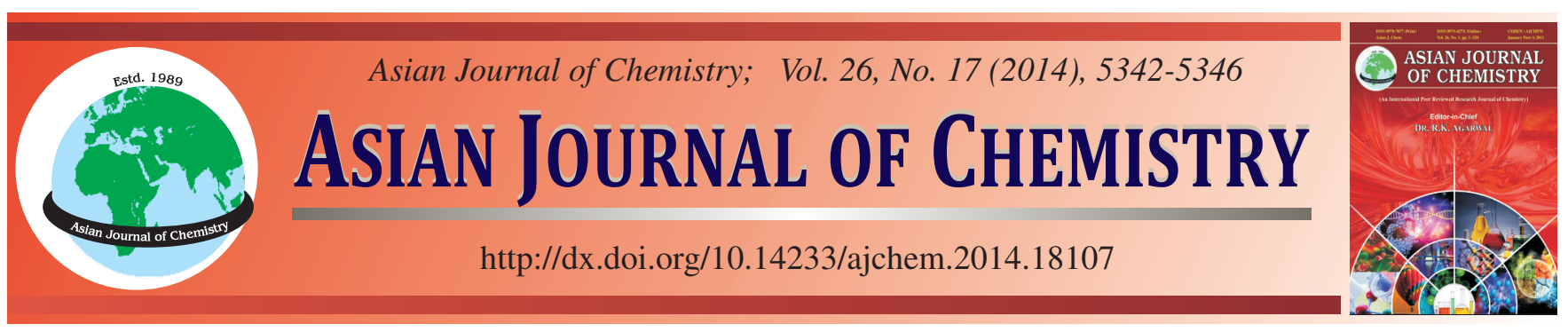

\title{
Physical Simulation Test for Developing Composite Materials of Non-Hydrophilic Aquifuge in Water-Preserved Mining $\dagger$
}

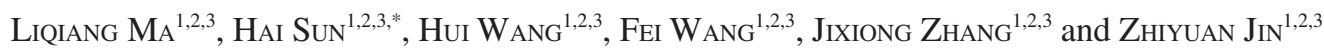

${ }^{1}$ School of Mines, China University of Mining \& Technology, Xuzhou 221116, Jiangsu Province, P.R. China

${ }^{2}$ Key Laboratory of Deep Coal Resource Mining, Ministry of Education of China, Xuzhou 221116, Jiangsu Province, P.R. China

${ }^{3}$ State Key Laboratory of Coal Resource \& Safe Mining, Xuzhou 221116, Jiangsu Province, P.R. China

*Corresponding author: Fax: +86 516 83590567; E-mail: ckma@cumt.edu.cn

With the fluid-solid coupling similar principle, composite materials of aquifuge are developed by physical simulation test for fluid-solid coupling in water-preserved mining and a rational proportion of non-hydrophilic is studied. Sand and gypsum are adopted as the aggregate of physical simulation materials, while vaseline and silicone oil are served as cementing agent. Firstly, water-physical properties of the material, including water absorption, permeability, distensibility and fluid-solid coupling softening effect, have been studied. Then, basic mechanical property of the material, plasticity has been tested on this basis. Finally, a series of rational proportions fit for aquifuge materials have been discovered, i.e., the weight ratios of sand and gypsum is between 5:1 and 7:1, aggregate and cementing agent between 6:1 and 8:1 and vaseline and silicone oil between $1: 1$ and 3:1. The research results not only can provide a basis for the research of waterpreserved mining by physical simulation test, but also can be used for other engineering projects in need of non-hydrophilic composite materials with good plasticity.

Keywords: Similar material, Fluid-solid coupling, Non-hydrophilic, Aquifuge.

\section{INTRODUCTION}

Western regions of China belong to arid and semi-arid climate, with poor water resources, where ecological environment is fragile, while large quantities of water resources occur in the phreatic aquifer. Massive loss of water resources in the phreatic aquifer caused by coal mining is bound to exacerbate further deterioration of the local environment and threaten ecological security ${ }^{1}$. Therefore, water-preserved mining must be implemented ${ }^{2}$.

The key to water-preserved mining research is to study the stability of aquifuge. Physical simulation test of fluid-solid coupling in laboratory can truly reveal the mining-induced rock strata movement, the development law of fissures and the change law for impermeable performance of aquiclude, which is one of key methods for water-preserved mining research ${ }^{3}$. However, the ratio of similar material, especially the ratio of aquifuge similar materials, is still being explored unceasingly. The property of similar materials adopted for the simulation of aquifuge determines the practical value of physical simulation effects.
Currently, the simulation of non-hydrophilic similar materials is widely adopted for the study of aquifuge similar materials. Two aspects of issues mainly exist. On one hand, the study of fluid-solid coupling is not theoretically mature enough. On the other, it is extremely difficult to find the material which can concurrently fit for solid deformation and permeability. Taking sand as an aggregate and paraffin as a cementing agent to simulate aquifuge. Qingxiang et $a l .{ }^{4}$ have successfully obtained a set of ratio range to simulate Lishi loess and Hipparion red clay. However, great efforts are needed in search of the best simulation of aquifuge. Taking sand and talc powder as an aggregate and paraffin as a cementing agent to blend up into coupling material, Li et al. ${ }^{5}$ have solved the problem of disintegration of solid model materials when wet, by adopting paraffin similar materials. Nevertheless, its preparation process has comparatively stringent requirements for temperature and other conditions, which is unsuitable for the application of large-scale simulation test.

In this paper, the principle of fluid-solid coupling similarity theory is adopted. It is proposed to take sand and gypsum as an aggregate and silicone oil and vaseline as a cementing 
agent to develop aquifuge similar simulation materials in considering the property of aquifuge under thick aeolian sand layer in Shendong mining area.

\section{EXPERIMENTAL}

Similarity theory for fluid-solid coupling: The similarity theory for fluid-solid coupling has been deduced by adopting the mathematical model ${ }^{6}$ of fluid-solid coupling of uniform continuous media. Following relationship equation has been obtained:

$$
\mathrm{C}_{\mathrm{G}}=\frac{\mathrm{c}_{\mu}}{\mathrm{c}_{1}^{2}}=\mathrm{C}_{\lambda} \frac{\mathrm{c}_{\varepsilon}}{\mathrm{c}_{1}}=\mathrm{C}_{\mathrm{G}} \frac{\mathrm{c}_{\varepsilon}}{\mathrm{c}_{1}}=\mathrm{C}_{\gamma}=\mathrm{C}_{\rho} \frac{\mathrm{c}_{\mu}}{\mathrm{c}_{\mathrm{t}}^{2}}
$$

where, $\mathrm{C}_{\mathrm{G}}, \mathrm{C}_{\mu}, \mathrm{C}_{1}, \mathrm{C}_{\lambda}, \mathrm{C}_{\gamma}, \mathrm{C}_{\varepsilon}, \mathrm{C}_{\rho}$ and $\mathrm{C}_{\mathrm{t}}$ represent for elastic modulus of shear, displacement, geometry, Lame constant, volume weight, volume, density and similar time scale, respectively.

From the eqn. 1, the requirements for model similarity is $\mathrm{C}_{\mathrm{G}}=\mathrm{C}_{\lambda}$; for geometric similarity is $\mathrm{C}_{\lambda}=\mathrm{C}_{\varepsilon} \mathrm{C}_{\mathrm{l}}$, due to geometric similarity after deformation, thus $\mathrm{C}_{\varepsilon}=1$, then $\mathrm{C}_{\mu}=\mathrm{C}_{1}$; for gravity similarity is $\mathrm{C}_{\mathrm{G}} \mathrm{C}_{\varepsilon}=\mathrm{C}_{\gamma} \mathrm{C}_{1}$ and as $\mathrm{G}=\mathrm{E} /(2(1+\mu))$, here $\mu$ is Poisson's ratio, thus $C_{G}=C_{E}$ and as $C_{\varepsilon}=1$, then $C_{E}=C_{\lambda} C_{1}$; for stress similarity is $\mathrm{C}_{\sigma}=\mathrm{C}_{\mathrm{E}} \mathrm{C}_{\varepsilon}$, then:

$$
\mathrm{C}_{\sigma}=\mathrm{C}_{\gamma} \mathrm{C}_{1}
$$

The similarity theory for fluid-solid coupling has been deduced based on the mathematical model of fluid-solid coupling of uniform continuous media. The similarity relation between penetration similar scale $\mathrm{C}_{\mathrm{k}}$, geometric similarity scale $\mathrm{C}_{\mathrm{k}}$ and volume weight similarity scale $\mathrm{C}_{\gamma}$ is as follows:

$$
\mathrm{C}_{\mathrm{k}}=\frac{\sqrt{\mathrm{c}_{1}}}{\mathrm{c}_{\gamma}}
$$

\section{Development of aquifuge similar materials}

Features of aquifuge: Currently, water-preserved mining is mainly implemented in Shendong mining area. As the effect of water-preserved mining depends on the stability of aquifuge impacted by mining, so we developed non-hydrophilic aquifuge similar materials in considering the property of aquifuge under thick aeolian sand layer in Shendong mining area.

The aquifuge under thick aeolian sand layer in Shendong mining area generally consists of clay, loam and sandy loam and also mingled with calcareous concretion layer and paleosol layer. Its aquifuge has the plasticity (plasticity index is between
7.5 and 13.1), combinability, low permeability (between 0.005 and $1.5 \mathrm{~m} / \mathrm{d}$ ) and low intensity (uniaxial compressive strength approximately between 120 and $210 \mathrm{kPa}$ ).

When parameters of uniaxial compressive strength of aquifuge are substituted into eqn. 2, the uniaxial compressive strength of composite aquifuge similar simulation materials can be obtained between 13-30 kPa. When parameters of permeability of aquifuge are substituted into eqn. 3 , the permeability of composite aquifuge similar simulation materials can be obtained between $0.011-3.50 \mathrm{~mm} / \mathrm{h}$.

Selection of raw materials: To fit for material property, the grain size of sand shall not be greater than $2 \mathrm{~mm}$ with uniform gradation; the gypsum shall be superfine high quality gypsum powder with fineness over 300 mesh; vaseline shall be non-toxic medical grade white vaseline; and silicone oil shall be simethicone with viscosity of 1,500 cs.

Orthogonal test design: The method of orthogonal ${ }^{7}$ test is adopted. Material ratios are shown in Table-1.

Preparation of the specimen: Based on the nature of the material ${ }^{8}$ component, the preparation process is divided into following steps: Weigh aggregate and cementing agent in accordance with the preparation ratio of specimen; Mingle sand and gypsum with appropriate amount of water to stir evenly; Heat the mixture of silicone oil and vaseline up to 45 and $60{ }^{\circ} \mathrm{C}$ and vaseline melted into liquid and mixed with silicone oil; stir evenly the well-prepared aggregate and cementing agent and load it into the mould and compact it; compact the mould and store it for about 20 days and demould and cure it at room temperature. The specimen is shown in Fig. 1.

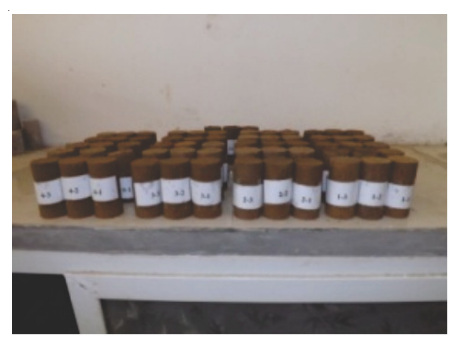

Fig. 1. Specimen

\section{RESULTS AND DISCUSSION}

\section{Parameters of permeability}

Water absorption: Water absorption test is shown in

\begin{tabular}{|c|c|c|c|c|c|c|c|c|}
\hline \multicolumn{9}{|c|}{$\begin{array}{l}\text { TABLE-1 } \\
\text { AQUIFUGE SIMILAR MATERIAL RATIOS ORTHOGONAL }\end{array}$} \\
\hline Number & $\begin{array}{l}\text { Aggregate: } \\
\text { cementing }\end{array}$ & $\begin{array}{l}\text { Sand: } \\
\text { gypsum }\end{array}$ & $\begin{array}{l}\text { Sand } \\
(\mathrm{g})\end{array}$ & $\begin{array}{l}\text { Gypsum } \\
\text { (g) }\end{array}$ & $\begin{array}{l}\text { Vaseline: } \\
\text { silicon oil }\end{array}$ & $\begin{array}{l}\text { Silicon oil } \\
\text { (g) }\end{array}$ & Vaseline (g) & $\begin{array}{l}\text { Specimens } \\
\text { weight }(\mathrm{g})\end{array}$ \\
\hline 1 & $7: 1(1)$ & $6: 1(1)$ & 1125 & 187.5 & $1: 1(1)$ & 93.75 & 93.75 & 1550 \\
\hline 2 & $7: 1(1)$ & $7: 1(2)$ & 1172.5 & 140 & $1: 2(2)$ & 62.5 & 125 & 1550 \\
\hline 3 & $7: 1(1)$ & $8: 1(3)$ & 1166.7 & 145.8 & $1: 2.5(3)$ & 54 & 133.5 & 1550 \\
\hline 4 & $8: 1(2)$ & $6: 1(1)$ & 1143.3 & 190 & $1: 2(2)$ & 55.6 & 111.1 & 1550 \\
\hline 6 & $8: 1(2)$ & $8: 1(3)$ & 1185.2 & 148.1 & $1: 1(1)$ & 83.35 & 83.35 & 1550 \\
\hline 7 & $9: 1(3)$ & $6: 1(1)$ & 1157 & 193 & $1: 2.5(3)$ & 42.8 & 107.2 & 1550 \\
\hline 8 & $9: 1(3)$ & $7: 1(2)$ & 1181.3 & 168.7 & $1: 1(1)$ & 75 & 75 & 1550 \\
\hline 9 & $9: 1(3)$ & $8: 1(3)$ & 1200 & 150 & $1: 2(2)$ & 50 & 100 & 1550 \\
\hline
\end{tabular}
Fig. 2. Water absorption ' $a$ ' is selected as a characteristic parameter of aquifuge similar materials and its equation is as follows: 


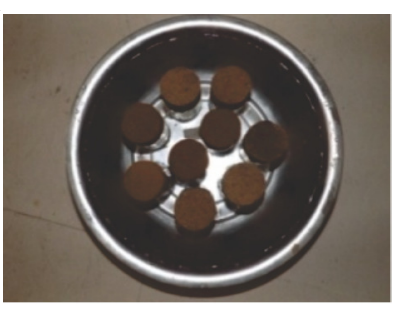

Fig. 2. Water absorption test

$$
\mathrm{a}=\frac{\mathrm{m}_{\mathrm{wet}}}{\mathrm{m}_{\mathrm{dry}}}
$$

where, ' $a$ ' is the water absorption, $\mathrm{m}_{\text {wet }}$ is the water absorption of the specimen immersed in water for $12 \mathrm{~h}$ and $\mathrm{m}_{\text {dry }}$ is the dry mass of the specimen prior to immersion.

To ensure reliable test data, water absorption data for five specimens of each group (totally 20 groups) have been made a standard error analysis. Table-2 shows the results of standard error for water absorption under the condition that the weight ratio of sand and gypsum is 7:1 and aggregate and cementing agent is $6: 1$.

\begin{tabular}{ccc}
\multicolumn{3}{c}{ TABLE-2 } \\
STANDARD ERROR FOR WATER ABSORPTION \\
\hline $\begin{array}{c}\text { Water } \\
\text { absorption } \\
\left(\mathrm{a}_{\mathrm{i}}\right)\end{array}$ & Residual $\left(\mathrm{a}_{\mathrm{i}}-\overline{\mathrm{a}}_{\mathrm{i}}\right)$ & $\left(\mathrm{a}_{\mathrm{i}}-\overline{\mathrm{a}}_{\mathrm{i}}\right)^{2}$ \\
\hline 0.0129 & $-4.2 \times 10^{-4}$ & $17.64 \times 10^{-8}$ \\
0.0134 & $8 \times 10^{-5}$ & $64 \times 10^{-10}$ \\
0.0135 & $1.8 \times 10^{-4}$ & $3.24 \times 10^{-8}$ \\
0.0135 & $1.8 \times 10^{-4}$ & $3.24 \times 10^{-8}$ \\
0.0133 & $-2 \times 10^{-5}$ & $4 \times 10^{-10}$ \\
\hline $\begin{array}{c}\text { Average } \\
\text { value }\end{array}$ & $\sum_{\mathrm{i}=1}^{5}\left(\mathrm{a}_{\mathrm{i}}-\overline{\mathrm{a}}_{\mathrm{i}}\right)=0$ & $\sum_{\mathrm{i}=1}^{5}\left(\mathrm{a}_{\mathrm{i}}-\overline{\mathrm{a}}_{\mathrm{i}}\right)^{2}=2.59 \times 10^{-7}$ \\
$\overline{\mathrm{a}}_{\mathrm{i}}=0.01332$ &
\end{tabular}

Standard error: $\sigma_{\mathrm{a}_{\mathrm{i}}}= \pm \sqrt{\frac{\sum_{\mathrm{i}=1}^{5}\left(\mathrm{a}_{\mathrm{i}}-\mathrm{a}_{\mathrm{i}}\right)^{2}}{5-1}}= \pm 5.0969 \times 10^{-4}$

$$
2 \sigma_{\mathrm{a}_{\mathrm{i}}}= \pm 10.19 \times 10^{-4}
$$

Upon examination, the residuals of observed value are all less than $2 \sigma_{a_{\mathrm{i}}}$, without gross error, indicating that experimental data for water absorption are accurate and reliable. Relation curves for material water absorption are shown in Fig. 3.

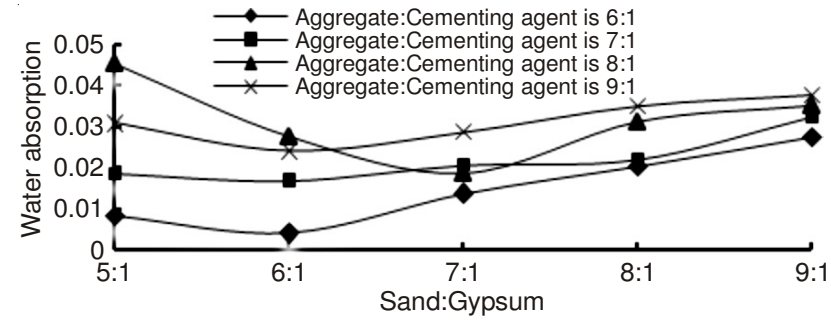

Fig. 3. Water absorption of the specimen

Following conclusions have been obtained from the relation of water absorption of the material: Water absorptions of all specimens are in between 0.4 and $4.5 \%$, they attribute to non-hydrophilic aquifuge similar materials. The case that the weight ratio of sand and gypsum is $6: 1$, when the weight ratio of aggregate and cementing agent is $6: 1$, the water absorption of the specimen reaches its minimum, which is $0.405 \%$; when the weight ratio of aggregate and cementing agent is $7: 1$, the water absorption of the specimen is $1.68 \%$. The water absorption is increased by 3 times, compared with the weight ratio of aggregate and cementing agent of $6: 1$. When the weight ratio of sand and gypsum is between 5:1 and 6:1, the water absorption is mainly determined by the hydrophilicity of gypsum. With the content of gypsum decreases, the water absorption of the specimen is also gradually decreased. When the weight ratio of sand and gypsum is between $6: 1$ and 7:1, water absorption of the specimen gradually increased again. When the weight ratio of sand and gypsum is over 7:1, relatively much more storage space occurs in the material. As non-hydrophilicity decreases, it cannot fit for non-hydrophilicity of aquifuge materials. Therefore, the weight ratio of sand and gypsum that can fit for non-hydrophilicity of aquifuge materials is between 5:1 and 7:1.

Permeability: The permeability of the material determines whether the material can fit for aquifuge ${ }^{9}$. As both the permeability of the material and the flow of water are smaller, the water level is difficult to control. Therefore, the falling head permeameter is adopted for the test. Permeability test is shown in Fig. 4.

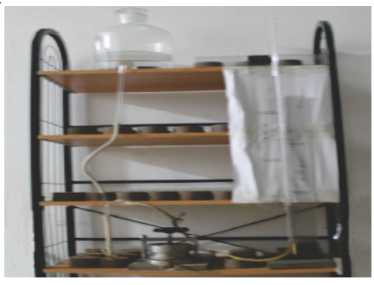

Fig. 4. Permeability test

Permeability index $\mathrm{v}$ is adopted to represent the permeable capacity of the material and the defining equation is as follows:

$$
\mathrm{v}=\frac{l}{\mathrm{t}}
$$

where: $l$ is the axial length of immersion in water, $\mathrm{mm}$; $\mathrm{t}$ is the permeability time, $\mathrm{h}$.

By means of the test, the permeation rate of several specimens with typical ratio for similar materials can be calculated by eqn. 5 , as shown in Table- 3 .

\begin{tabular}{cccc}
\multicolumn{5}{c}{ TABLE-3 } \\
PERMEATION RATE OF SEVERAL SPECIMENS \\
\hline \multirow{2}{*}{ Number } & $\begin{array}{c}\text { Vaseline: } \\
\text { silicone oil }\end{array}$ & $\begin{array}{c}\text { Gypsum } \\
\text { content }(\%)\end{array}$ & $\begin{array}{c}\text { Permeation } \\
\text { rate }(\mathrm{mm} / \mathrm{h})\end{array}$ \\
\hline 1 & $2: 1$ & 14.5 & 4.32 \\
2 & $1: 1$ & 14.5 & 3.54 \\
3 & $1: 1$ & 20 & 3.17 \\
4 & $1: 2$ & 14.5 & 2.46 \\
\hline
\end{tabular}

Derived from Table-3, the permeation rate of the specimen reduces with the decrease of the weight ratio of silicon oil and vaseline. The content of gypsum has relatively large impact 
on the permeation rate of the specimen. The increase of the content of gypsum causes the material much denser, thus, the permeation rate of the specimen is reduced.

Distensibility: The reason that aquifuge can maintain good impermeable performance after fissures occur is inseparable with the property of the secondary closure occurred in aquifuge which can make fissures distensile when wet. This is the distensibility of aquifuge $\mathrm{e}^{10}$, which is the key factor of aquifuge in control of stability.

The degree of distensibility of fissures is related to the distensile material when wet, therefore, the expansion rate of the material when wet is adopted to represent the distensibility of the material.

In the simulation of similar materials, the main element that impacts the distensibility of the material is gypsum. Standard error estimation has been made for each set of data, removing unreasonable experimental data. The variation in expansion rate of the specimen is shown in Fig. 5.

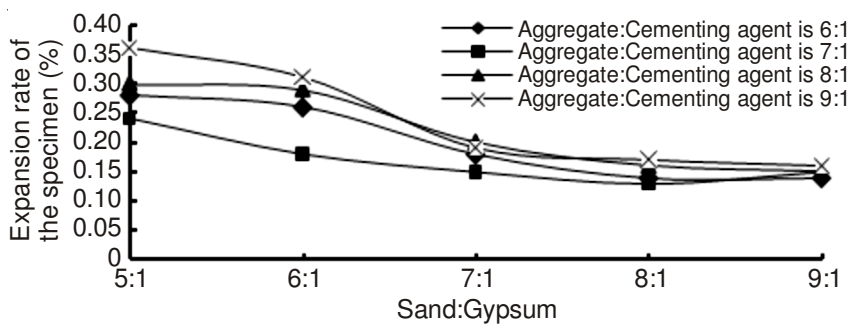

Fig. 5. Expansion rate of the specimen

Following conclusions have been obtained from variation curves in the expansion rate of the specimen: When the weight ratio of sand and gypsum is between 5:1 and 6:1, the expansion rate of the specimen is relatively high and its value is between 0.18 and $0.36 \%$, which is mainly determined by the expansion property of gypsum when wet. When the weight ratio of sand and gypsum is between $7: 1$ and 9:1, the expansion rate of the specimen is basically the same, which is due to the decrease of the content of gypsum and the result of its expansibility contributing less to the expansion rate of the specimen. When the weight ratio of sand and gypsum is between $5: 1$ and 7:1, the expansion rate of the material is relatively large and the distensibility can fit for aquifuge similar materials.

Softening effect: The test for the specimen is processed in three ways, i.e., non-immersion, immersion for 10 days and immersion for 30 days. Then, the compressive strength of the specimen is tested and its results are shown in Table-4. Following conclusions have been obtained from the comparison of the compressive strength of the specimen immersed in water for different period of time: For specimen immersed in water for 10 days, the softening effect is extremely small. For instance, in the case of the weight ratio of aggregate and cementing agent is 7:1, when the weight ratio of sand and gypsum is, respectively 5:1, 6:1 and 7:1, the compressive strength of the specimen is decreased by $3.31,0.8$ and $3.16 \%$, correspondingly. The compressive strength is basically invariable between the specimen immersed in water for 30 days and 10 days. For instance, in the case of the weight ratio of aggregate and cementing agent is $7: 1$, when the weight ratio of sand and gypsum is, respectively $5: 1,6: 1$ and $7: 1$, the compressive strength of the specimen is decreased by $1.47 \%$, increased by $0.4 \%$ and decreased by $1.82 \%$, correspondingly. The compressive strength of the specimen shows no significant change with the extension of immersion time and the softening range can be ignored.

Weight ratio of vaseline and silicone oil: The impact of the weight ratio of vaseline and silicon oil of the material ${ }^{11}$ on compressive strength and permeation rate of the material has been studied in the test (Fig. 6).

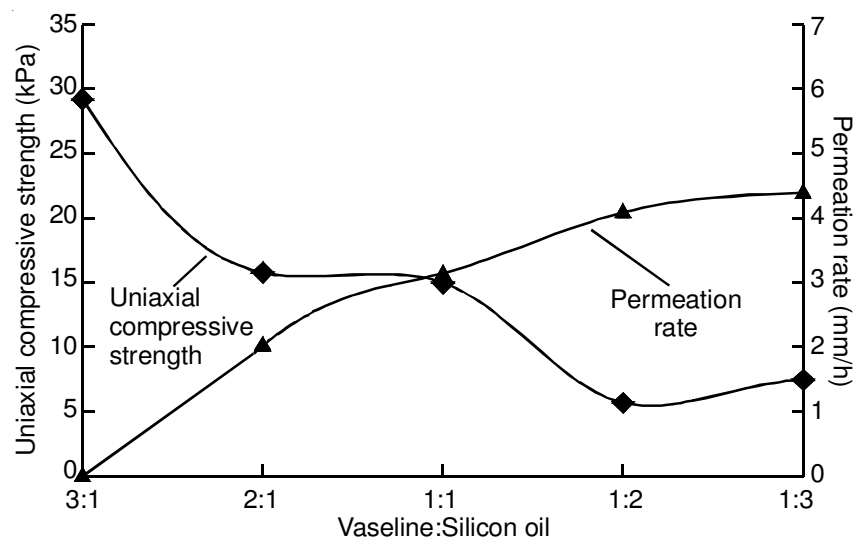

Fig. 6. Impact of the weight ratio of vaseline and silicon oil to the similiar material

Following conclusions have been obtained from influence curves of the weight ratio of vaseline and silicon oil on the similar material: The impact of the weight ratio of vaseline and silicon oil on compressive strength of the material is particularly significant. For instance, when the weight ratio of vaseline and silicon oil decreases from 3:1 to 2:1, the compressive strength of the material decreases from $28.79-16.56 \mathrm{kPa}$, decreased by $42.4 \%$. When the weight ratio of vaseline and silicon oil decreases to $1: 3$, the compressive strength of the material is only $7.39 \mathrm{kPa}$. With the same water head pressure, when the weight ratio of vaseline and silicon oil is $3: 1$, the permeation rate of the material is almost zero. With the decrease of silicon oil in the proportion, the permeation rate is continually increased. When the weight ratio of vaseline and silicon

\section{TABLE-4}

\section{COMPRESSIVE STRENGTH OF THE SPECIMEN IMMERSED IN WATER FOR DIFFERENT PERIOD OF TIME}

\begin{tabular}{|c|c|c|c|c|c|c|}
\hline Sand: gypsum & \multicolumn{2}{|r|}{$5: 1$} & \multicolumn{2}{|r|}{$6: 1$} & \multicolumn{2}{|r|}{$7: 1$} \\
\hline $\begin{array}{l}\text { Soaking time } \\
\text { (d) }\end{array}$ & $\begin{array}{l}\text { Density } \\
\left(\mathrm{g} \mathrm{cm}^{-3}\right)\end{array}$ & $\begin{array}{l}\text { Uniaxial compressive } \\
\text { strength }(\mathrm{kPa})\end{array}$ & $\begin{array}{l}\text { Density } \\
\left(\mathrm{g} \mathrm{cm}^{-3}\right)\end{array}$ & $\begin{array}{l}\text { Uniaxial compressive } \\
\text { Strength }(\mathrm{kPa})\end{array}$ & $\begin{array}{l}\text { Density } \\
\left(\mathrm{g} \mathrm{cm}^{-3}\right)\end{array}$ & $\begin{array}{l}\text { Uniaxial compressive } \\
\text { Strength }(\mathrm{kPa})\end{array}$ \\
\hline 0 & 2.023 & 14.77 & 2.087 & 25.98 & 2.112 & 15.79 \\
\hline 10 & 2.102 & 14.28 & 2.107 & 25.76 & 2.127 & 15.29 \\
\hline 30 & 2.106 & 14.09 & 2.116 & 25.87 & 2.131 & 14.98 \\
\hline
\end{tabular}

Note: weight ratios of aggregate and cementing agent of these specimens are 7:1. 
TABLE-5

PERFORMANCE PARAMETERS OF SOME TYPICAL SPECIMENS

\begin{tabular}{|c|c|c|c|c|c|}
\hline $\begin{array}{l}\text { Number of } \\
\text { test block }\end{array}$ & $\begin{array}{c}\text { Material mixture ratio } \\
\text { (S:G:V:S) }\end{array}$ & $\begin{array}{l}\text { Uniaxial compressive } \\
\text { strength } \sigma(\mathrm{kPa})\end{array}$ & $\begin{array}{c}\text { Plasticity index } \\
\alpha(\mathrm{kPa})\end{array}$ & $\begin{array}{c}\text { Water absorption a } \\
(\%)\end{array}$ & $\begin{array}{l}\text { Expansion rate of the } \\
\text { specimen } \partial(\%)\end{array}$ \\
\hline 1 & 1: 0.2:0.13:0.066 & 13.24 & 0.70 & 0.81 & 0.28 \\
\hline 2 & 1: 0.2:0.11:0.057 & 14.77 & 0.714 & 1.84 & 0.24 \\
\hline 3 & 1: 0.2:0.1:0.05 & 16.25 & 0.78 & 4.52 & 0.30 \\
\hline 4 & 1: $0.17: 0.13: 0.065$ & 21.91 & 0.916 & 0.40 & 0.26 \\
\hline 5 & 1: $0.17: 0.11: 0.055$ & 25.98 & 0.94 & 1.68 & 0.18 \\
\hline 6 & 1: 0.17:0.097:0.049 & 24.96 & 1.0 & 2.75 & 0.29 \\
\hline 7 & 1:0.14:0.12:0.06 & 14.26 & 1.34 & 1.35 & 0.18 \\
\hline 8 & 1:0.14:0.10:0.05 & 15.79 & 1.41 & 2.06 & 0.15 \\
\hline
\end{tabular}

oil is between $1: 1$ and $3: 1$, the performance requirements for aquifuge similar materials can be met in respect of both strength and permeability.

Plasticity index: When the yield limit is exceeded, the specimen will have relatively large deformation under comparatively small stress. Therefore, the capacity of deformation of the specimen decreased with the stress after it yields and reach the peak strength is selected to express stress-strain characteristics of plastic section of the specimen, i.e., plastic characteristic parameter:

$$
\alpha=\frac{\sigma_{1}-\sigma_{2}}{\varepsilon_{2}-\varepsilon_{1}}
$$

where, $\alpha$ is plastic characteristic parameter; $\sigma_{1}$ is peak compressive strength of the specimen; $\sigma_{2}$ is residual strength of the material; $\varepsilon_{1}$ is strain capacity under peak strength of the material, while $\varepsilon_{2}$ is the strain capacity under residual strength of the material.

It can be known from eqn. 6 that, the smaller the plastic characteristic parameter of the specimen $\alpha$ is, the more obvious the plastic property of the test piece is. The variation in plastic change characteristics of the specimen is shown in Fig. 7.

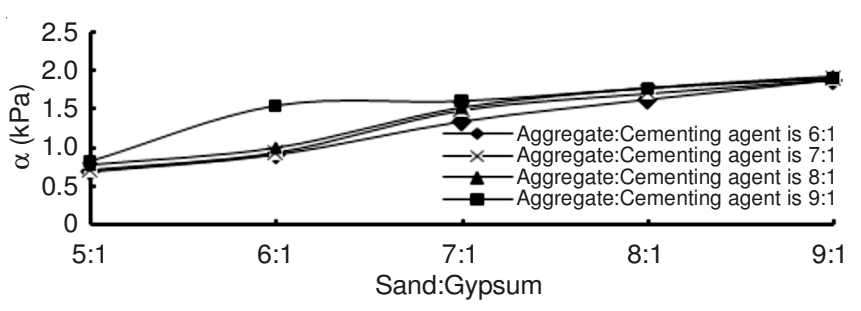

Fig. 7. Plastic change characteristics of the specimen

Following conclusions have been obtained from plastic change characteristics of the specimen: The plastic characteristic parameter $\alpha$ value is increasing with the increase of the weight ratio of sand and gypsum. For instance, with the same weight ratio of aggregate and cementing agent, when the weight ratio of sand and gypsum is $6: 1$, the value is 0.916 $\mathrm{kPa}$; when the weight ratio of sand and gypsum is $7: 1$, the value is $1.34 \mathrm{kPa}$, increased by $46.3 \%$ comparatively. When the weight ratio of sand and gypsum is between $5: 1$ and 7:1 and the weight ratio of aggregate and cementing agent is between $6: 1$ and $8: 1$, the plastic properties of the material can fit for aquifuge similar materials. Performance parameters of some typical specimens are shown in Table-5.

\section{Conclusion}

When the weight ratios of sand and gypsum is between 5:1 and 7:1, aggregate and cementing agent between $6: 1$ and $8: 1$ and vaseline and silicone oil between $1: 1$ and $3: 1$, the material can fit for the simulation of aquifuge. The distensibility of the material is dominated by gypsum, which conduces to the simulation of secondary closure of fissures occurred in aquifuge to be distensile when wet. The plasticity of the material is dominated by vaseline, which conduces to the simulation of large deformation in aquifuge at low intensity. The nonhydrophilicity of the material is dominated by silicone oil, which conduces to the simulation of water-physical properties of aquifuge. Aquifuge similar materials developed in research not only can be adopted in physical simulation test for waterpreserved mining, which has laid a solid foundation for the study of water-preserved mining, but can also be applied to other engineering projects in need of aquifuge materials with low intensity and good plasticity, such as the impermeable layer used at the bottom of refuse landfill to prevent groundwater from being contaminated by leachate.

\section{ACKNOWLEDGEMENTS}

This work was supported by "The Fundamental Research Funds for Central Universities (China University of Mining and Technology) with project No. 2014YC01 and Project Funded by the Priority Academic Program Development of Jiangsu Higher Education Institutions (SZBF2011-6-B35).

\section{REFERENCES}

1. V. Palchik, Environ. Geol., 44, 28 (2003).

2. H. Hanfu, W. Changshen, B. Haibo and W. Zihe, Int. J. Mining Sci. Technol., 22, 719 (2012).

3. Z. Bian, X. Miao, S. Lei, S. Chen, W. Wang and S. Struthers, J. Sci., 337, 702 (2012).

4. Q. Huang, W. Zhang and Z. Hou, Chin. J. Rock Mechanics Eng., 29, 2813 (2010).

5. S. Li, X. Feng and S. Li, Chin. J. Rock Mechanics Eng., 29, 281 (2010).

6. Y.D. Liu, D.S. Zhang, G.W. Fan and S.F. Yan, Min. Sci. Technol., 21, 381 (2011).

7. L. Ma, X. Du and F. Wang, Disaster Adv., 6, 268 (2013).

8. L. Ma, X. Cao and Q. Liu, Environ. Eng. Manage. J., 12, 1797 (2013).

9. M. Souley, F. Homand, S. Pepa and D. Hoxha, J. Int. J. Rock Mechanics Mining Sci., 38, 297 (2001).

10. L. Li, M. Qian and Y. Yin, Coal Geol. Explor., 25, 33 (1996).

11. H. Pu, X. Miao, B. Yao and M. Tian, J. China Univ. Mining Technol., 18, 353 (2008). 